\title{
Ensuring the Reliability of Fire-Arm Identification Evidence
}

T Mutsavi $^{\star}$ and L Meintjes van der Walt ${ }^{\star \star}$

\section{P.E.R}

Pioneer in peer-reviewed,

open access online law publications

Authors

Tanyarara Mutsavi

Lirieka Meintjes-van der Walt

Affiliation

University of Fort Hare

South Africa

Email

mutsavitanyarara@gmail.com

Imeintjes-vanderwalt@ufh.ac.za

Date Submission

13 February 2019

Date Revised

21 January 2020

Date Accepted

21 January 2020

Date published

20 May 2020

Editor Prof T Mmusinyane

How to cite this article

Mutsavi T and Meintjes van der

Walt $L$ "Ensuring the Reliability of

Fire-Arm Identification Evidence"

PER / PELJ 2020(23) - DOI

http://dx.doi.org/10.17159/1727-

3781/2020/v23i0a6046

Copyright

DOI

http://dx.doi.org/10.17159/17273781/2020/v23i0a6046

\begin{abstract}
Notwithstanding the acceptance of firearm identification by courts, the scientific community has been reluctant to recognise firearm identification as a reliable method of conclusively establishing a connection between a particular bullet and a particular gun. The National Institute of Justice (NIJ) in the United States (US) has categorised firearm identification as a discipline under forensic science, and forensic science has been described as a "fractured and burdened discipline". In addition, in 2009 the National Academy of Sciences (NAS) concluded that forensic science is broken. With regard to firearm identification, the NAS Report emphasised the need for sufficient studies to be done because this report regarded this type of evidence as unreliable and lacking repeatability. The President's Council of Advisors on Science and Technology (PCAST) Report, released in September 2016, came to a conclusion similar to that of the 2009 NAS Report with regard to forensic science evidence. With regard to firearm identification, the report asserted that firearm identification evidence still "falls short of the scientific criteria for foundational validity". It is disturbing that courts across the globe are using different types of forensic science without subjecting them to scrutiny so as to determine their reliability. In the light of this, reliability and validity have become important factors which demand attention in Anglo-American litigation, even in jurisdictions that do not have a formal reliability standard (such as England and Wales, and South Africa). This article shows the role of cross-examination in establishing the reliability of firearm expert evidence. It also focusses on the role that South African forensic practitioners, prosecutors, defence counsels and presiding officers can play in ensuring the reliability of firearm identification evidence.
\end{abstract}

\section{Keywords}

Firearm identification; reliability; validity; cross-examination; relevance; forensic science; cartridge; bullet; criminal justice; firearm. 


\section{Introduction}

The research which informs this article was prompted by the fact that the relevant scientific community has reservations regarding the way in which firearm identification has traditionally been accepted in courts, and is sceptical with regard to the assumption that current firearm identification methods can conclusively establish a connection between a specific bullet and a particular firearm. The National Institute of Justice (NIJ) in the United States (US) has categorised firearm identification as a discipline under forensic science,${ }^{1}$ and forensic science has been described as a "fractured and burdened discipline". ${ }^{2}$ This scepticism is compounded by the fact that, in 2009 the National Academy of Sciences (NAS) concluded that forensic science is broken. ${ }^{3}$ With regard to firearm identification, the NAS Report emphasised the need for more studies to be done, because this report regarded this type of evidence as unreliable and lacking repeatability. The President's Council of Advisors on Science and Technology (PCAST) Report, released in September 2016, came to a conclusion similar to that of the 2009 NAS Report with regard to forensic science evidence. ${ }^{4}$ This report concluded that firearm identification evidence "still falls short of the scientific criteria for foundational validity". Despite this negative criticism of firearm identification evidence, courts across the globe still use different types of forensic science without subjecting them to scrutiny so as to determine their reliability. ${ }^{5}$ In the light of this, reliability and validity have become important factors which demand attention in Anglo-American litigation, even in jurisdictions that do not have a formal reliability standard (such as England and Wales, and South Africa). ${ }^{6}$ The aim of this article is to investigate the

Tanyarara Mutsavi. LLB (UFH) LLM (UFH). E-mail: mutsavitanyarara@gmail.com. ORCiD: https://orcid.org/0000-0002-3298-0360. LLM candidate University of Fort Hare, South Africa. The article is partially based on the first author's LLM thesis titled The Reliability of Firearm Identification in South Africa: A Comparative Perspective (UFS 2018).

* $\quad$ Lirieka Meintjes-van der Walt. BJuris LLB (UPE) LLM (Rhodes) DJuris (Leiden) Adjunct Professor and Leader of the Law, Science and Justice Research Niche Area, Nelson Mandela School of Law, Faculty of Law, University of Fort Hare, South Africa. E-mail: Imeintjes-vanderwalt@ufh.ac.za. ORCiD: https://orcid.org/0000-0001-75678957.

1 Commission on Identifying the Needs of the Forensic Science Community Strengthening Forensic Science in the United States 38 (hereinafter 2009 NAS Report).

2 Gabel 2014 J Crim L \& Criminology 284.

32009 NAS Report xx.

$4 \quad$ President's Council of Advisors Report to the President 11 (hereinafter 2016 PCAST Report).

$5 \quad$ Gabel 2014 J Crim L \& Criminology 284.

$6 \quad$ Edmond et al 2013 U Denv Crim L Rev 31. 
role of cross-examination in establishing the reliability of firearm expert evidence, and the discussion below focuses on the role that South African forensic practitioners, prosecutors, defence counsel and presiding officers can play in ensuring the reliability of firearm identification evidence.

\section{Firearm identification}

Firearm identification is "the forensic science discipline that identifies a bullet, cartridge case or other ammunition components as having been fired by a particular firearm".7

If a firearm is fired, a number of the gun's features are conveyed to the cartridge casings and bullets, thereby making distinctive patterns called striae or scratch marks. ${ }^{8}$ These marks, also called tool marks, are made each time the firearm is fired and they are formed as a result of the primer which detonates and the gunpowder which burns, resulting in the expansion of the casing in all directions, causing the imprinting of the casing and ammunition by the breech face of the gun. ${ }^{9}$ The internal part of a gun is hard and that is why, when it gets into contact with the softer metal of the bullet and casings, it results in the making of marks on the casings and ammunition. ${ }^{10} \mathrm{~A}$ firearm examiner purports to match bullets and cartridges to the weapon from which they originated by comparing bullets test-fired from a recovered gun with the spent bullets from the scene, using a comparison microscope to do so. ${ }^{11}$

\section{The role of forensic practitioners in ensuring reliability}

Forensic practitioners, such as firearm examiners, should use mainstream scientific methods and norms. ${ }^{12}$ According to Edmond et al, mainstream scientific methods will- ${ }^{13}$

facilitate compliance with the formal requirements imposed by courts (e.g. admissibility standards and practice directions) and professional codes; improve performance; reduce mistakes and misrepresentations; and insulate practitioners and their institutions from criticism and external interference.

Giannelli, Imwinkelried and Peterson "Reference Guide on Forensic Identification Expertise" 548. Inbau 1999 J Crim L \& Criminology 1296.

United States v Green 405 F Supp 2d 104, 110 (D Mass 2005).

Schwartz 2005 Colum Sci \& Tech L Rev 6.

2009 NAS Report 153.

This refers to the commitment to testing and standardising procedures in regular use. See Mulkay 1976 Soc Sci Inf 637.

Edmond et al 2016 AJFS 2. 
Practitioners should furthermore ensure that there is "disclosure", "transparency", and "impartiality" with regard to the information provided to prosecutors, defence lawyers and judges when they give testimony and in their reports. ${ }^{14}$ This would assist the court to comprehend how the evidence was collected, processed and analysed ${ }^{15}$ in order to make it easier to determine the probative value of forensic science evidence and to determine the credibility of the practitioner.${ }^{16}$ The main function of the expert witness is to help judges to "administer justice" through the provision of impartial expert opinion and testimony. ${ }^{17}$

\section{The role of prosecutors in achieving the reliability of firearm identification}

Edmond contends that prosecutors play an important role in the recognition and "social legitimating" of different types of expert evidence. ${ }^{18}$ Should prosecutors be tempted to trivialise problems regarding the scientific reliability of firearm identification, trials and appeals might not be doing enough to regulate firearm identification and other types of forensic science. ${ }^{19}$ This could lead to miscarriages of justice and the "pursuit of truth" could be threatened. ${ }^{20}$

Gershman elucidates that "the prosecutor dominates the system, has exclusive control of the evidence, and decides how that evidence will be used."21 Responding to the decision in Daubert $v$ Merrell Dow Pharmaceuticals, ${ }^{22}$ several American scholars share the view that prosecutors should ensure reliability by guarding against unsubstantiated

\footnotetext{
14 See Mnookin et al 2011 UCLA L Rev 725.

152009 NAS Report 21.

16 See the discussion by the Supreme Court of Canada in White Burgess Langille $v$ Abbott and Haliburton Co 2015 SCC 23.

17 Impartiality requires that forensic practitioners discharge their responsibilities to assist the court to reach an accurate conclusion, including by explaining uncertainties and limitations - rather than conceiving of their role as one of assisting the police or the prosecution to secure a conviction. See Cunliffe 2013 AJFS 284.

18 See Edmond 2013 UNSWLJ 936:"[P]rosecutors, by using unreliable forensic evidence and questionable expert witnesses, and judges, by failing to exercise their gatekeeping role in a sufficiently diligent manner, have become part of the mechanism by which misconvictions occur."

19 Edmond 2013 UNSWLJ 930.

20 Ho Philosophy of Evidence Law 35.

21 Gershman 2003 Okla City U L Rev 17, 18. Also see Green and Zacharias 2004 Wis L Rev 837; Luna and Wade 2010 Wash \& Lee L Rev 1413.

22 Daubert v Merrell Dow Pharmaceuticals Inc 509 US 579 (1993). Also see General Electric Co v Joiner 522 US 136 (1997); Kumho Tire Co v Carmichael 526 US 137 (1999).
} 
incriminating expert evidence. ${ }^{23}$ They further argue that "unreliable, weak and speculative forensic science would be far less of a problem if trial mechanisms consistently identified and conveyed limitations with expert evidence". ${ }^{24}$

Nonetheless, it has emerged that prosecutors sometimes adduce forensic science and leave the defence to identify and explain its weaknesses and limitations through cross-examination. ${ }^{25}$ However, prosecutors should on their own obtain information about the "limitations and oversights" with regard to expert opinion evidence. ${ }^{26}$ Defence lawyers might lack resources and they might not be sufficiently technically literate to recognise and explain the weaknesses in forensic science. ${ }^{27}$ According to Edmond et al, prosecutors and forensic practitioners need to refer to "validation studies", "limitations", "error rates" and "controversies" so that the defence and judges will find out about them. ${ }^{28}$

\section{The importance of cross-examination in achieving reliability in firearm identification}

Black's Law Dictionary defines cross-examination as "the questioning of a witness upon a trial or hearing, or upon taking a deposition, by the party opposed to the one who produced him." ${ }^{29}$ Cross-examination is not just a

Moriarty $2007 \mathrm{Neb} L \operatorname{Rev} 1$, 3. Moriarty, for example, proposes that expert evidence should not be adduced if there is "a factual basis to believe that the proposed evidence is incorrect, inaccurate, incomplete, misleading or without solid foundation." Raeder 2007 Fordham L Rev 1413. Also see Saks 2001 Clev St L Rev 421. Raeder endorses Saks's proposal for attention to validity and a reasonable good faith belief in reliability - a "good faith basis for believing". Giannelli and McMunigal 2007 Fordham L Rev 1493. Giannelli and McMunigal propose supplementing the (US) Model Rules with an obligation preventing prosecutors from "knowingly, recklessly, or negligently offering false scientific evidence."

"There is also the problem of lay decision-making in legal contexts. This is not simply a question of jury (and judicial) competence, but the more complex issue of evaluating evidence in circumstances that are not always conducive to decisionmaking. This includes restricted exposure to information, limited ability to ask questions, inability to consult additional materials or discuss beyond the jury and so on." See Irwin and Wynne Misunderstanding Science? 53. Edmond et al 2016 AJFS 11. Velevski v The Queen 2002187 ALR 233.

Edmond et al 2016 AJFS 34:"This is analogous to the need for the prosecution to call all material witnesses so they can be cross-examined by the defense. Problems and limitations with forensic science evidence should be raised by the state, so the defense knows about them and can explore them if this is considered appropriate." Edmond et al 2016 AJFS: "Moreover, it is more likely that limitations (including serious methodological and technical issues) will be seen as trivial or motivated if raised by the defense rather than introduced and explained by the prosecutor." 
privilege but it is a right which a party is given to confront testimony from an opposing witness. ${ }^{30}$ No statement should be used as testimony in the court system until it has been challenged by the opposing party. ${ }^{31}$

\subsection{Relevance}

In South Africa expert evidence is accepted only if it is relevant. ${ }^{32}$ The actual reliability of the expert evidence does not play an important role at the admissibility stage of the evidence but during trial, through crossexamination or when the opposing side adduces evidence, the reliability of the evidence can be attacked. ${ }^{33}$ It is during the cross-examination stage that counsel is obliged to be conversant with and attend to the concerns of mainstream scientific organisations and the attentive community of scholars. ${ }^{34}$ The Law Commission of England and Wales supports this argument in its report by saying it is through cross-examination that "the adduction of contrary expert evidence and judicial guidance at the end of the trial are currently assumed to provide sufficient safeguards in relation to expert evidence." 35

Acharya shares this view and asserts that "a keystone feature of the adversarial system is its ability, through properly resourced and informed cross-examination to best reveal and illuminate areas of scientific controversy." 36 He further believes that cross-examination is there to expose "inconsistencies" and "improprieties" in scientific evidence. ${ }^{37}$

The questions asked in the course of cross-examination should be centred on establishing "experimental validation", "measures of reliability" and "proficiency", because these factors provide some information about "actual ability" and "accuracy" that makes it possible for expert evidence to be rationally evaluated by judges. This, as against focussing on things like qualifications, experience, common knowledge and previous admission. ${ }^{38}$

\footnotetext{
30 Resurrection Gold Mining Co v Fortune Gold Mining Co 129 F 668 (8 $8^{\text {th }}$ Cir 1904).

$31 \quad$ Black 1988 SUL Rev 397.

32 Cromwell 2011 http://www.scottishlawreports.org.uk/publications/macfadyen2011.html.

33 Edmond and Meintjes-van der Walt 2014 SALJ 113.

$34 \quad$ Edmond 2013 UNSWLJ 931.

35 Law Commission Expert Evidence in Criminal Proceedings 59.

36 Acharya 2013 Dalhousie LJ 135.

37 Acharya 2013 Dalhousie LJ 135.

$38 \quad 2009$ NAS Report 94. Also see Edmond 2015 Adel L Rev 76.
} 


\subsection{Validation}

When required to establish the weight to be attached to firearm identification, presiding officers in South Africa could derive significant assistance from the criteria for reliability and admissibility accepted in the landmark case of Daubert. The reliability criteria for "determining the admissibility of scientific evidence" established in this case could assist South African presiding officers in determining the weight which should be attached to firearm identification evidence. ${ }^{39}$ This includes whether the theory or technique: 40

a) can be and has been tested; b) whether it has been subjected to peerreview and publication; c) whether the technique employed by the expert is generally accepted in the scientific community; d) whether the known or potential rate of error is known; and; e) whether the research was conducted independent of the particular litigation or dependent on an intention to provide the proposed testimony.

Presiding officers might find it helpful to apply the four Daubert criteria when they are required to evaluate the scientific value of firearm/tool mark examiners' conclusions regarding striated tool mark identity. ${ }^{41}$ In the aftermath of Daubert, commentators like Koehler pointed out that forensic science is no longer regarded to be as infallible as it was in the past. ${ }^{42} \mathrm{He}$ accentuated several factors such as the fallibility of forensic science in "crime lab scandals, fraud, unsupported assumptions, high profile errors, and wrongful convictions", ${ }^{43}$ which underlined the potential fallibility of some forensic disciplines.

Reliable scientific evidence is required to be based on a theory that is testable and falsifiable. ${ }^{44}$ Meintjes-van der Walt likens falsifiability to refutability or testability. She goes on to say that "in order for a theory to be scientific, it must make predictions concrete enough to be proved wrong if the claim is not true." 45 In relation to this, the court in United States $v$ Green ${ }^{46}$ stated that: ${ }^{47}$

$39 \quad$ Meintjes-van der Walt 2003 J Afr L 101.

$40 \quad$ Daubert v Merrell Dow Pharmaceuticals Inc 509 US 579 (1993).

$41 \quad$ Grzybowski and Murdock 1998 AFTE Journal 3.

$42 \quad$ Koehler and Meixner $2016 \mathrm{~J}$ Crim L \& Criminology 7.

$43 \quad$ Koehler and Meixner $2016 \mathrm{~J}$ Crim L \& Criminology 7.

44 Meintjes-van der Walt 2003 J Afr L 101; Thornton 1994 Shepard's Expert and Scientific Evidence Quarterly 478.

$45 \quad$ Meintjes-van der Walt Expert Evidence in the Criminal Justice Process 203.

$46 \quad$ United States $v$ Green 405 F Supp 2d 104 (D Mass 2005).

$47 \quad$ United States $v$ Green 405 F Supp 2d 104 (D Mass 2005). 


\begin{abstract}
When liberty hangs in the balance ... the standards should be higher than ... have been imposed across the country. The more courts admit this type of tool mark evidence without requiring documentation, proficiency testing, or evidence of reliability, the more sloppy practices will endure; we should require more.
\end{abstract}

South African courts, while possibly not consistently so, also require the testing of an expert's opinion when the weight of the evidence is decided. In the South African case of $R v$ Jacobs, ${ }^{48}$ many years before Daubert, Ramsbottom J held that: 49

... it is of the greatest importance that the value of the opinion should be capable of being tested and unless the expert states the grounds upon which he bases his opinion, it is not possible to test its correctness so as to form a proper judgment upon it.

Legal decision-makers need to take note of the conclusion of the The Ballistic Imaging Report that "[t]he validity of the fundamental assumptions of uniqueness and reproducibility of firearms-related tool marks has not yet been fully demonstrated."50 The adequacy of the empirical basis of firearm identification expertise, therefore, is still not conclusive and research in this regard is still in progress. ${ }^{51}$

Presiding officers should decide whether experts testify on matters growing "naturally and directly" out of research they conducted "independent of the litigation", or whether they have developed their opinions expressly for the purposes of testifying. ${ }^{52}$ The court in In Re: Paoli Railroad Yard PCB Litigation stated that testimony based on "legitimate, pre-existing research unrelated to the litigation" constitutes the "most persuasive" grounds for deciding on the scientific grounds for the testimony of a forensic expert. ${ }^{53}$

Daubert indicates that peer-review is an important way means by which a court can determine the scientific validity and reliability of expert testimony. In terms of this paradigm, the scientific method of the particular identification process has to be peer-reviewed by other experts in the field. According to Grzybowski and Murdock, peer-review refers to the "the specific process of evaluation that requires knowledge of the scientific method." 54 Accordingly,

48

49

50

51

52

53

54

$R v$ Jacobs 1940 TPD 142, 146; Twine $v$ Naidoo 20181 All SA 297 (GJ). Also see Bee $v$ Road Accident Fund 20184 SA 366 (SCA).

$R v$ Jacobs 1940 TPD 142, 146.

$R v$ Jacobs 1940 TPD 142, 146.

2016 PCAST Report 32. Also see Nichols 2007 Journal of Forensic Science 586. Also see Schwartz 2005 Colum Sci \& Tech L Rev 6.

In Re Paoli Railroad Yard PCB Litigation 35 F 3d 717 (3rd Cir 1994) 741.

In Re Paoli Railroad Yard PCB Litigation 35 F 3d 717 (3rd Cir 1994) 742.

Grzybowski and Murdock 1998 AFTE Journal 9. 
in order to comply with the requirements of scientific method, firearm identification should be published in a professional peer-reviewed journal: ${ }^{55}$

\begin{abstract}
The peer-review process will involve the assessment of the following:(1) the validity of the hypothesis; (2) how it was formulated and tested; (3) whether the scientific method was followed; and (4) whether proper conclusions were reached.
\end{abstract}

The Journal of Forensic Sciences, the official journal of the American Academy of Forensic Sciences (AAFS), together with others of "similar substance", utilise a peer-review process for firearm evidence. ${ }^{56}$ Although the Association of Firearm and Tool Mark Examiners (AFTE) journal claims to be peer-reviewed, ${ }^{57}$ the court in US $v$ Diaz ${ }^{58}$ did not recognise the AFT Journal as a peer-reviewed journal, citing the fact that it does not meet the basic requirements of a peer-reviewed journal.

It seems as if firearm and tool mark examiners often peer-review one another's work after identification has been reached. This has been recognised by some legal commentators as the source of confirmation bias. ${ }^{59}$ Mahoney defines confirmation bias as "a phenomenon whereby scientists tend to settle on a theory at the outset and thereafter tend to look for data to confirm the theory, rather than trying to discredit or refute it." 60 Confirmation bias can give some value to evidence that is in favour of a person's opinion or version of events. ${ }^{61}$ Commenting on the same issue, Dutton elucidates that "[i]f the expert doing the check only ever checks positive matches, then the perception will be that whenever he sits at the microscope to conduct a peer-review of casework, he will expect to see a positive match."62

More criticism has emerged with regard to the peer-reviewing process in the disciplines of forensic science. According to Cooper, forensics analysts are often from the law enforcement field instead of a particular scientific field, ${ }^{63}$ which has the effect that the forensic science disciplines tend to be rooted

\footnotetext{
55 Grzybowski et al 2003 AFTE Journal 11.

56 Grzybowski et al 2003 AFTE Journal 11.

57 Grzybowski et al 2003 AFTE Journal 11.

58 United States v Diaz No CR 05-00167 WHA, 2007 WL 485967 (ND Cal Feb 12, 2007) (hereinafter US v Diaz).

$59 \quad$ In US $v$ Diaz 5 it was held that: "[t]he industry standard requires confirmation by at least one separate examiner when an identification is reached by the first examiner."

$60 \quad$ Mahoney Scientist as Subject 155.

61 Hogan Lovells 2016 https://www.hoganlovells.com/en/publications/confirmationbias-and-the-law.

62 Dutton 2005 AFTE Journal 80.

63 Cooper 2016 JPSL 7.
} 
in research that has application which is only about criminal investigations and law enforcement and not about knowledge per se. As a result "these disciplines can be fragmented, poorly regulated and lack standardised procedures." 64 Research regarding scientific methods in these areas can be limited, unpublished and narrowly circulated, and there is often a lack of will to pursue the validation of the methods employed. ${ }^{65}$

Experimental evidence to determine whether "a technique does what it purports to, and how well" is reached by means of validation. If the techniques are validated on the basis of empirical evidence, they will produce stable and consistent results. Validation also provides the appropriate framework to assess abilities and levels of performance. ${ }^{66}$

\subsection{Limitations and errors}

\subsubsection{Error rates}

According to Edmond et al, validation studies provide information about "the circumstances in which a technique is known to work, how well it works as well as its limitations." 67 As a result, the testimony given in court must provide limitations and information about potential sources of error. ${ }^{68}$ An expert opinion that does not reveal the basis on which it is grounded and which does not disclose its known limitations is incomplete. Furthermore, it "creates a serious risk of being misunderstood, and contravenes the expert's overriding duty impartially to assist the court."69 It is difficult to

Although it should certainly be noted that the implementation and following of "standardized procedures" in forensic science identification methods do not automatically produce scientifically valid or reliable results. The NRC Report reached this very conclusion in relation to the ACE- $V$ procedure used by fingerprint examiners:"[m]erely following the steps of ACE-V does not imply that one is proceeding in a scientific manner or producing reliable results." 2009 NAS Report 142. The NRC Report made a similar conclusion in relation to the AFTE protocol associated with tool-mark examination. "This AFTE document, which is the best guidance available for the field of toolmark identification, does not even consider, let alone address, questions regarding variability, reliability, repeatability, or the number of correlations needed to achieve a given degree of confidence." 2009 NAS Report 155.

65 Laurin 2015 Tex L Rev 1761.

66 Daubert v Merrell Dow Pharmaceuticals Inc 509 US 579 (1993) and Tuite $v$ The Queen 2015 VSCA 148 suggest that the trustworthiness or "reliability" of the evidence adduced by forensic science should be demonstrated by evidence of validity.

$67 \quad$ Edmond et al 2014 Aust Bar Rev 177.

68 Edmond et al 2014 Aust Bar Rev 177.

69 "The fact that any error rate will be somewhat artificial and might not capture the precise conditions of the analysis is not an excuse. Awareness of this issue did not 
evaluate the value of the practitioner's evidence when there is no indication of the error rate. ${ }^{70}$

The third element to determine reliability as stipulated in Daubert is the determination of the error rate of the method which is being used. Error rate refers to the frequency with which one deviates or strays from a correct standard. ${ }^{71}$ In cases involving firearms, experts are called to give testimony on whether the firearm in question can be identified as the source of a questioned tool mark or not. In these instances, presiding officers also need to know "how often such identifications are in error". ${ }^{72}$ In other words, they want to know "how often the profession, using accepted techniques and controls, produces a mistaken identity."73

In firearm identification the only international source of proficiency testing from which potential error rates can be inferred is the Collaborative Testing Service (CTS). ${ }^{74}$ The 1978 Crime Laboratory Proficiency Testing Program in the USA registered "mixed results" regarding CTS results for firearm identification. ${ }^{75}$ In one of the tests conducted, $5.3 \%$ of the laboratories that took part in the test misidentified firearms evidence. In another one, 13.6\% of the laboratories erred. ${ }^{76}$ The tests were done on the basis of bullet and cartridge case comparisons. The Project Advisory Committee held that these errors were "particularly grave in nature" and concluded that "they probably resulted from carelessness, inexperience, or inadequate supervision." 77 In the 1978-2005 period, less than 5\% of responses were in error, but individual test results varied. ${ }^{78}$ In some instances $30 \%$ to $40 \%$ of the replies were not conclusive, because the laboratories were not sure if the tool in question had been altered between the times when different markings were made. During this period, inconclusive responses remained

prevent the NAS and other groups insisting that these should be determined and disclosed." See the 2009 NAS Report 184, 122.

The lack of research might prevent appropriate qualifications being made. Edmond et al 2016 AJFS 36.

71 Grzybowski et al 2003 AFTE Journal 8.

72 Puzniak 2000 Court Review 40.

73 Grzybowski et al 2003 AFTE Journal 12.

74 Nichols 2006 California Association of Criminalists News 24. Collaborative Testing Services Inc. 2018 https://cts-forensics.com/program-3.php. CTS offers the greatest variety of proficiency tests to meet the diverse needs of the firearms and toolmarks community and works with that community to create casework-like samples that challenge examiners and assess their performance.

75 Breyer Reference Manual on Scientific Evidence 97.

76 Breyer Reference Manual on Scientific Evidence 97.

77 Breyer Reference Manual on Scientific Evidence 97.

78 Breyer Reference Manual on Scientific Evidence 97. 
frequent for firearms testing. ${ }^{79}$ Examiners in most cases stated that they were not able to come to a conclusion because of the unavailability of the actual weapon to test-fire ammunition. ${ }^{80}$ In this context, questions and criticisms have arisen concerning the significance of these tests. One of the criticisms is that the sample for proficiency testing to determine error rate is "self-selecting and may not be representative of the complete universe of firearms examiners". ${ }^{81}$ Moreover, the examinations are not blind. That is, examiners know when they are being tested. As a result, the examiner is likely to be more careful than in ordinary case work. ${ }^{82}$ In relation to this, the 2008 Ballistic Imaging Report stated that most of these studies are limited in scale and have been conducted by firearms examiners (and examiners in training) in state and local law enforcement laboratories as adjuncts to their regular casework. ${ }^{83}$

In regard to the factor of "known or potential error", the court in US v Diaz held that "it is not possible to calculate an absolute error rate for firearms identification." ${ }^{84}$ This is partly because the standards and criteria for traditional pattern matching are subjective. ${ }^{85}$ Furthermore, the court ended by stating that "No true error rate will ever be calculated so long as the firearm-examiner community continues to rely on the subjective traditional pattern matching method of identification." ${ }^{86}$ This means that currently no true error rate for firearm identification is known.

\subsubsection{Inadequacies of the AFTE Theory of Identification}

In regard to the above, the Association of Firearm and Tool Mark Examiners (AFTE) in a review in its journal under the heading "Theory of Identification, Range of Striae Comparison Reports and Modified Glossary Definitions" discusses the discipline of forensic firearm and tool mark identification and also gives the "basic theory that allows opinions of common origin to be

\footnotetext{
79 Breyer Reference Manual on Scientific Evidence 97.

$80 \quad$ Breyer Reference Manual on Scientific Evidence 97.

81 United States $v$ Monteiro United 407 F Supp 2d 351 (D Mass 2006) (hereinafter US $\checkmark$ Monteiro).

82 Breyer Reference Manual on Scientific Evidence 98.

83 Committee to Assess the Feasibility, Accuracy, and Technical Capability of a National Ballistics Database Ballistic Imaging 16 (hereinafter 2008 Ballistic Imaging Report).

84 US $v$ Diaz 8.

85 US $v$ Diaz 8.

86 US v Diaz 8.
} 
made in tool mark comparisons."87 The AFTE Theory of Identification adopted in 1992 states:

1. The theory of identification as it pertains to the comparison of tool marks enables opinions of common origin to be made when the unique surface contours of two tool marks are in 'sufficient agreement'.

2. This 'sufficient agreement' is related to the significant duplication of random tool marks as evidenced by a pattern or combination of patterns of surface contours. Significance is determined by the comparative examination of two or more sets of surface contour patterns comprised of individual peaks, ridges and furrows. Specifically, the relative height or depth, width, curvature and spatial relationship of the individual peaks, ridges and furrows within one set of surface contours are defined and compared to the corresponding features in the second set of surface contours. Agreement is significant when it exceeds the best agreement demonstrated between tool marks known to have been produced by different tools and is consistent with agreement demonstrated by tool marks known to have been produced by the same tool. The statement that 'sufficient agreement' exists between two tool marks means that the agreement is of a quantity and quality that the likelihood that another tool could have made the mark is so remote as to be considered a practical impossibility.

3. Currently the interpretation of individualization/identification is subjective in nature, founded on scientific principles and based on the examiner's training and experience. ${ }^{88}$

The NAS Report suggests that the AFTE theory of identification does not give a specific protocol, because the theory states that an examiner can give "an opinion that a specific firearm was the cause of a bullet striation pattern when sufficient agreement exists in the pattern of two sets of marks", ${ }^{89}$ which is a subjective determination. In addition, the AFTE theory contends that "agreement is significant when it exceeds the best agreement demonstrated between tool marks known to have been produced by different tools and is consistent with the agreement demonstrated by tool marks known to have been produced by the same tool." 90 In this regard, the 2009 NAS Report comments that the meaning of "exceeds the best agreement" and "consistent with" are not clearly established, and the examiner is expected to "draw on his or her own experience". 91 The AFTE theory is also described as being circular, in the PCAST Report, because it

AFTE Criteria for Identification Committee 1992 AFTE Journal 337.

AFTE Criteria for Identification Committee 1992 AFTE Journal 337.

2009 NAS Report 155.

2009 NAS Report 153.

2009 NAS Report 155. 
suggests that an examiner has the capacity to state that "two tool marks have a common origin when their features are [in] sufficient agreement."92

The AFTE theory shows that "[c]urrently the interpretation of individualization/identification is subjective in nature". ${ }^{93}$ It is crucial to note that under the subjective approach, examiners rely only on their mind and eye judgments in identifying resemblances instead of articulating the criteria which they used to arrive at conclusions with regard to the resemblances. ${ }^{94}$ Nichols poses the question, "with subjective standards/criteria, how does one determine if either examiner has made an error?"95 In US $v$ Monteiro Judge Saris stated that the AFTE theory is "tautological: it requires each examiner to decide when there is 'sufficient agreement' of tool marks to constitute identification." 96 Judge Saris further criticised the AFTE theory for not providing examiners with any guidance on telling the difference between subclass and individual characteristics. ${ }^{97}$ The judge held that: ${ }^{98}$

Because an examiner's bottom line opinion as to identification is largely a subjective one ${ }^{99}$ there is no reliable statistical or scientific methodology which will currently permit the expert to testify that it is a 'match' to an absolute certainty, or to an arbitrary degree of statistical certainty.

In Ramirez $v$ State of Florida ${ }^{100}$ the Supreme Court criticised firearm and tool mark examiners who rely on "nothing more than their own subjective criteria for striae identification" and are unable to put forth "a convincing, logical, scientifically based explanation for the basis of their identifications." 101

922016 PCAST Report 60. In response to PCAST's concern about this circularity, the FBI Laboratory replied that: "'Practical impossibility' is the certitude that exists when there is sufficient agreement in the quality and quantity of individual characteristics." This answer did not address the issue helpfully. AFTE Criteria for Identification Committee 1992 AFTE Journal 336.

Schwartz 2005 Colum Sci \& Tech L Rev 14.

Nichols 2006 California Association of Criminalists News 11.

US v Monteiro 370.

US $v$ Monteiro 371. The Judge expressed concern that the examiner who made the identifications indicated that he does not even consider subclass characteristics when he examines breech face markings. US v Monteiro 372.

99 Instead of articulating criteria, most examiners rely solely on subjective, mind's eye judgments of when the resemblances between tool marks are sufficient to justify identity conclusions. See Schwartz 2008 The Champion 44.

100 Ramirez $v$ State of Florida (Florida Supreme Court) (unreported) case number SC92975 of 20 December 2001.

101 Nichols 2006 California Association of Criminalists News 2. 
The AFTE Theory is based on the assumption that interpretations based on forensic science are founded on an examiner's training and experience. ${ }^{102}$ The PCAST Report, however, states that experience is not enough for one to draw judgments about whether two features have come from different sources or the same source. To show the fallacy of relying on "experience", the PCAST Report refers to the testimony of a former head of the FBI, in which he claimed that "the FBI had an error rate of one per every 11 million cases", based on the fact that the agency was aware of only one mistake. ${ }^{103}$ This observation has been questioned in empirical studies by the FBI Laboratory which indicate a high error rate of roughly one in several hundred. ${ }^{104}$ Speaking at the Ninth Circuit Judicial Conference, Mnookin contended that "[i]t must take scientific study to make a field scientifically reliable". ${ }^{105}$ Mnookin further said that "[e]xperience, no matter how extensive, could not be a substitute for scientific study". ${ }^{106}$ Moreover, Edmond believes that prosecutors, defence lawyers and judges should direct attention to formal evidence of reliability and not rely on evidence founded on the extent of the experience of the witness. ${ }^{107}$

A theory of science has been defined by the NAS to mean "a comprehensive explanation of some aspect of nature that is supported by a vast body of evidence." ${ }^{108}$ Accepting this definition, the PCAST Report contends that the AFTE theory of identification is clearly not a scientific theory. Instead, "it is a claim that examiners applying a subjective approach can accurately individualise the origin of a tool mark." 109 The report goes on to say that a "theory" is not what is needed at the moment but only empirical tests to figure out how reliable and valid the method is. ${ }^{110}$

Moreover, in the late 1990s, the AFTE drafted a protocol (the AFTE Protocol) for experts to follow during their examinations. ${ }^{111}$ According to the AFTE protocol: ${ }^{112}$

\footnotetext{
102 AFTE Criteria for Identification Committee 1992 AFTE Journal 123.

103 US v Baines 573 F 3d 979 (2009) 984 as cited in the 2016 PCAST Report 45.

104 US v Baines 573 F 3d 979 (2009) 984 as cited in the 2016 PCAST Report 45.

105 Dinzeo 2017 https://www.courthousenews.com/skepticism-forensic-methods-urged9th-circuit-conference.

106 Dinzeo 2017 https://www.courthousenews.com/skepticism-forensic-methods-urged9th-circuit-conference.

107 Edmond 2015 Adel L Rev 94.

108 See the National Academies of Sciences Engineering Medicine 2008 https://www.nas.edu/evolution/TheoryOrFact.html.

1092016 PCAST Report 60.

1102016 PCAST Report 60.

111 AFTE Glossary 1998 AFTE Journal 86.

112 Koen and Bowers Forensic Science Reform 178.
} 
... an examiner may make one of the following four conclusions: (1) identification, (2) inconclusive, (3) elimination, or (4) unsuitable for comparison. To make an 'identification' (i.e., a 'match'), there must be 'sufficient agreement' between the tool-marks present on ammunition found at a crime scene and a test cartridge fired from a suspect weapon.

In spite of this protocol and the "routine admission of firearms identification evidence", the discipline has been criticised in the NAS and PCAST Reports. ${ }^{113}$ The 2009 NAS Report maintains that the AFTE document which has been described as the most important source of guidance in the discipline of firearm identification does not touch on issues of "variability, reliability, repeatability, or the number of correlations needed to achieve a given degree of confidence."114 The 2009 NAS Report concluded that the AFTE Protocol was not defined sufficiently for examiners to be able to follow it, particularly when an examiner can be said to have "matched" two samples. ${ }^{115}$

\subsection{Personal proficiency}

Edmond et al warn that the court cannot assess the probative value of the evidence in instances where the professional proficiency and the mastery of particular techniques on the part of the expert witness have not been validated. ${ }^{116}$

\subsection{Expressions of opinion}

Currently the examination of firearms involves human judgment. The expression of a forensic practitioner's opinion should be informed by experimental research based on a validated technique and based on the proficiency of forensic practitioners. Forensic practitioners should be in a position empirically to justify particular terminology or scales, and the justification should be clear and comprehensible.

In the NAS Report the National Research Council (NRC) Committee emphasised that there is a need to raise the standards for "reporting and testifying about the results" of investigations in most disciplines of forensic science. ${ }^{117} \mathrm{~A}$ good example is the use of some terms by forensic examiners in reports and in their court testimony in describing their findings and conclusions. These terms include "match", "consistent with", "identical",

\footnotetext{
113 Cooper 2014 TM Cooley L Rev 466.

1142008 Ballistic Imaging Report 155.

115 Cooper 2014 TM Cooley L Rev 468.

116 Edmond et al 2014 Aust Bar Rev 174.

1172009 NAS Report 185.
} 
"similar in all respects tested", and "cannot be excluded as the source of". ${ }^{118}$ The use of these terms can have some influence on how the presiding officer in court proceedings assesses and evaluates the evidence. Nonetheless, there has not been agreement or consensus on the exact meaning of the terms in forensic science. ${ }^{119}$ They have not been standardised, even if some fields of forensic science "have developed vocabulary and scales" which they use in reporting their results. ${ }^{120}$ Laboratory reports generated by scientific analysis should be thorough and should describe their- ${ }^{121}$

methods and materials, procedures, results, and conclusions, and they should identify, as appropriate, the sources of uncertainty in the procedures and conclusions which indicate the level of confidence in the results.

According to the NRC Committee, most forensic laboratory reports do not meet this standard of reporting, although some do. ${ }^{122}$ In addition to the above, the forensic science reports and courtroom testimony must present the limitations of the analyses, including the associated probabilities, where this is possible. The courtroom testimony should be given in clear terms that everyone engaged in the trial can understand, so as to be able to interpret the testimony. The NAS Report contends that this is achievable and that "research must be undertaken to evaluate the reliability of the steps of the various identification methods and the confidence intervals associated with the overall conclusions."123

Since the first assumption in firearm identification is that a mark can be individually related to the specific gun from which it was fired, some firearm analysts, when giving opinions of mark identity, have concluded that the firearm responsible for making the mark can be individualised "to the exclusion of all other tools". ${ }^{124}$ This conclusion has been strongly criticised by some commentators, who believe that it is problematic. ${ }^{125}$

2009 NAS Report 185.

2009 NAS Report 185.

2009 NAS Report 186.

2009 NAS Report 186.

2009 NAS Report 186.

2009 NAS Report 186.

Michelson Crime Scene Investigation 4.

Gunther 1932 Mechanical Engineering 334. Hatcher Textbook of Firearms Investigation 286. Gunther and Hatcher recognise this as impossible, since we cannot examine all tools in the world. Examiners and experts are still striving to make sure the process of individualisation is valid and reliable. With regard to this, in its 2009 report the NRC summarised the state of the research as follows: "Because not enough is known about the variabilities among individual tools and guns, we are not able to specify how many points of similarity are necessary for a given level of confidence in the result. Sufficient studies have not been done to understand the 
Notwithstanding this criticism, firearm identification evidence has been admitted into American courtrooms and is still being admitted. ${ }^{126}$

Murdock states that: ${ }^{127}$

Absolute certainty opinions may have been adopted in the past, but this type of position has been retired for some time and no longer represents the consensus thinking of the firearm and tool mark community.... [O]ur everyday lives are predicated upon practical certainty. ${ }^{128}$

Firearm identification became well known in the early $20^{\text {th }}$ century and by the middle of the twentieth century courts were admitting firearm testimony by firearm experts. ${ }^{129}$ Cases decided after the middle of the twentieth century relied on these previous cases for precedence in admitting evidence of bullet, ${ }^{130}$ cartridge case, ${ }^{131}$ and shot shell ${ }^{132}$ identifications. A number of courts have also permitted an expert to testify that "a bullet could have been

reliability and repeatability of the methods. The committee agrees that class characteristics are helpful in narrowing the pool of tools that may have left a distinctive mark. Individual patterns from manufacture or from wear might, in some cases, be distinctive enough to suggest one particular source, but additional studies should be performed to make the process of individualization more precise and repeatable." 2009 NAS Report 154.

Cooper 2016 JPSL 1. Also see Bonnie 2012 Suffolk J Trial \& App Advoc 57. 2009 NAS Report 186.

Murdock et al 2017 Journal for Forensic Science 625.

See People v Fisher 172 NE 743 (III 1930); Evans v Commonwealth 19 SW 2d 1091 (Ky 1929); Burchett $v$ State 172 NE 555 (Ohio Ct App 1930).

See United States $v$ Wolff 5 MJ 923926 (NCMR 1978); State v Mack 653 NE 2d 329 337 (Ohio 1995). The examiner "compared the test shot with the morgue bullet recovered from the victim, and the spent shell casings recovered from the crime scene, concluding that all had been discharged from appellant's gun."

Bentley $v$ Scully $41 \mathrm{~F} 3 \mathrm{~d} 818825$ (2d Cir 1994). "[A] ballistic expert found that the spent nine-millimeter bullet casing recovered from the scene of the shooting was fired from the pistol found on the rooftop." State $v$ Samonte 928 P 2d 1, 6 (Haw 1996) "Upon examining the striation patterns on the casings, [the examiner] concluded that the casing she had fired matched six casings that police had recovered from the house."

See Williams v State 384 So 2d 1205 1210-1211 (Ala Crim App 1980); Burge v State 282 So 2d 223229 (Miss 1973); Commonwealth v Whitacre 878 A 2d 96101 (Pa Sup Ct 2005): "no abuse of discretion in the trial court's decision to permit admission of the evidence regarding comparison of the two shell casings with the shotgun owned by Appellant." 
fired from a particular firearm; ${ }^{133}$ that is, the class characteristics of the bullet and the firearm are consistent."134

Court decisions made in 1993, soon after Daubert, to challenge the admissibility of firearm identification evidence, failed, ${ }^{135}$ but this position started to change after 2001.136 In a 2001 Daubert evaluation in United States $v$ Mikos $^{137}$ the court found that source conclusions based on bullet lead analysis were based on faulty science and were inadmissible. The court admitted the evidence of the FBI agent in that case to testify as to the chemical similarities in the bullets, but not as to any probability that they came from the same source. ${ }^{138}$

Moreover, in United States $v$ Green ${ }^{139}$ the court held that the expert could only tell "the ways in which the casings were similar" but not that "the casings came from a specific weapon to the exclusion of every other firearm in the world." 140 Although the judge allowed tool mark evidence in this case, he commented that: ${ }^{141}$

133 See People $v$ Horning 102 P 3d 228236 (Cal 2004), where the expert "opined that both bullets and the casing could have been fired from the same gun, but because of their condition he could not say for sure." In Luttrell $v$ Commonwealth 952 SW 2d 216218 (Ky 1997) the expert "testified only that the bullets which killed the victim could have been fired from Luttrell's gun."

134 This type of evidence has some probative value and satisfies the minimal evidentiary test for logical relevancy. See Federal Rules of Evidence 2020 https://www.rulesofevidence.org/article-iv/rule-401. As one court commented, the expert's "testimony, which established that the bullet which killed [the victim] could have been fired from the same caliber and make of gun found in the possession of [the defendant], significantly advanced the inquiry." Commonwealth $v$ Hoss $283 \mathrm{~A}$ 2d 5868 (Pa 1971).

135 See United States $v$ Hicks 389 F 3d 514526 (5th Cir 2004) ruling that "the matching of spent shell casings to the weapon that fired them has been a recognised method of ballistics testing in this circuit for decades"; United States v Foster $300 \mathrm{~F} \mathrm{Supp} \mathrm{2d}$ 375377 n 1 (D Md 2004): "Ballistics evidence has been accepted in criminal cases for many years. In the years since Daubert, numerous cases have confirmed the reliability of ballistics identification." See United States $v$ Santiago 199 F Supp 2d 101111 (SDNY 2002): "The Court has not found a single case in this Circuit that would suggest that the entire field of ballistics identification is unreliable."

136 Breyer Reference Manual on Scientific Evidence 101.

137 United States v Mikos No 02 CR 1372003 WL 22922197 (ND III 2003).

$138 \quad$ United States v Mikos No 02 CR 1372003 WL 22922197 (ND III 2003).

139 United States $v$ Green 405 F Supp 2d 104110 (D Mass 2005).

140 United States $v$ Green 405 F Supp 2d 104107 (D Mass 2005). The court had followed the same approach in a handwriting case. See United States $v$ Hines $55 \mathrm{~F}$ Supp 2d 6267 (D Mass 1999) expert testimony concerning the general similarities and differences between a defendant's handwriting exemplar and a stick-up note was admissible but not the specific conclusion that the defendant was the author. United States v Green 405 F Supp 2d 104110 (D Mass 2005). 
The more courts admit this type of tool mark evidence without requiring documentation, proficiency testing, or evidence of reliability, the more sloppy practices will endure; we should require more.

The court in United States $v$ Glynn ${ }^{142}$ was of the view that the expert should not use the term "reasonable scientific certainty" in testifying, but rather that the expert should be permitted to testify only that it was "more likely than not" that recovered bullets and cartridge cases came from a particular weapon. ${ }^{143}$

The district court in United States $v$ Ashburn, ${ }^{144}$ while declining to go as far as Green and Glynn in circumscribing source opinions, relied on the 2009 NAS Report and the criticisms of the AFTE sufficiency theory in the opinions discussed above to preclude "this expert witness from testifying that he is 'certain' or '100\%' sure [or] that a match he identified is to the exclusion of all other firearms in the world' or that there is a 'practical impossibility' that any other gun could have fired the recovered materials." 145

Another pertinent case which involved the reliability of firearm identification is the Ramirez case. ${ }^{146}$ Firearm experts had to be able to put forth "a convincing, logical, scientifically based explanation for the basis of their identifications." ${ }^{47}$ The court in this case rejected the argument by the expert that "I know it is a match because I have sufficient background, training and experience." The judge also rejected the argument by the firearm examiner that "there is absolute certainty of his identification and that there are no

$142 \quad$ United States $v$ Glynn 578 F Supp 2d 567 (SDNY 2008).

$143 \quad$ United States $v$ Natson 469 F Supp 2d 12531261 (MD Ga 2007): "According to his testimony, these tool marks were sufficiently similar to allow him to identify Defendant's gun as the gun that fired the cartridge found at the crime scene. He opined that he held this opinion to a $100 \%$ degree of certainty. The Court also finds [the examiner's] opinions reliable and based upon a scientifically valid methodology. Evidence was presented at the hearing that the tool mark testing methodology he employed has been tested, has been subjected to peer-review, has an ascertainable error rate, and is generally accepted in the scientific community". Commonwealth v Meeks Nos 2002-10961, 2003-10575, 2006 WL 281942350 (Mass Super Ct Sept $28,2006)$ : "The theory and process of firearms identification are generally accepted and reliable, and the process has been reliably applied in these cases. Accordingly, the firearms identification evidence, including opinions as to matches, may be presented to the juries for their consideration, but only if that evidence includes a detailed statement of the reasons for those opinions together with appropriate documentation." State v Davidson 509 SW 3d 156205 (Tenn 2017) where firearm identification was described as a "fingerprint".

$144 \quad$ United States $v$ Ashburn 88 F Supp 3d 239 (EDNY 2015).

$145 \quad$ United States $v$ Ashburn 88 F Supp 3d 239 (EDNY 2015).

146 Ramirez $v$ State of Florida (Florida Supreme Court) (unreported) case number SC92975 of 20 December 2001.

147 Ramirez $v$ State of Florida (Florida Supreme Court) (unreported) case number SC92975 of 20 December 2001. 
objective criteria that must be met." 148 Finally, in the Ramirez case the court found the examiner's scientific methodology had not gone through "meaningful peer-review or publication". ${ }^{149}$

In United States v Monteiro, ${ }^{150}$ after reviewing the Daubert requirements at length, the court found that firearm evidence was generally admissible but that the prosecution's witnesses were not qualified. Moreover, the judge held that: ${ }^{151}$

even a qualified government expert may testify that the cartridge cases were fired from a particular firearm to a reasonable degree of ballistic certainty. However, the expert may not testify that there is a match to an exact certainty.

In this case the expert had not taken photographs of the evidence to show the comparisons which had been made. In this regard the court ruled that: ${ }^{152}$

Until the basis for the identification is described in such a way that the procedure performed by [the examiner] is reproducible and verifiable, it is inadmissible under Rule 702.

When presenting firearm identification evidence to the court, the expert must satisfy the court according to Rule 702 with regard to the following four factors: 153

scientific, technical, or other specialized knowledge that will help the trier of fact to understand the evidence or to determine a fact in issue; the testimony is based on sufficient facts or data; the testimony is the product of reliable principles and methods; and the expert has reliably applied the principles and methods to the facts of the case.

These rules would be equally applicable in South Africa even although South Africa does not apply the Daubert rule for the purposes of admissibility. ${ }^{154}$

The court in United States $v$ Diaz, ${ }^{155}$ after finding that the record did not support the conclusion that identifications could be made to the exclusion of all other firearms in the world, held that "the examiners who testify in this

\footnotetext{
148 Ramirez $v$ State of Florida (Florida Supreme Court) (unreported) case number SC92975 of 20 December 2001.

149 Ramirez $v$ State of Florida (Florida Supreme Court) (unreported) case number SC92975 of 20 December 2001.

150 US v Monteiro 366

151 US v Monteiro 366.

152 US v Monteiro 366.

153 Federal Rules of Evidence 2011 https://www.law.cornell.edu/rules/fre/rule_702.

154 Faurie Admissibility and Evaluation of Scientific Evidence 26.

155 US v Diaz.
} 
case may only testify that a match has been made to a 'reasonable degree of certainty in the ballistics field."'156

In United States $v$ Taylor ${ }^{157}$ the court ruled that the government expert "will not be allowed to testify that he can conclude that there is a match to the exclusion, either practical or absolute, of all other guns." Furthermore, in US $v$ Anderson ${ }^{158}$ the court was of the view that a firearm examiner may testify to "a reasonable degree of certainty" in the field of firearms and tool mark identification or "to a practical certainty" but not to "a reasonable degree" of scientific certainty or a "practical impossibility". ${ }^{159}$

US $v$ Willock $^{160}$ joined the ranks of cases restricting the conclusions that may be offered in testimony by a firearms and tool mark examiner. Adopting a magistrate judge's Report and Recommendations ( $R$ \& $R$ ), ${ }^{161}$ the court ordered that the witness shall not express the opinion that it is a "practical impossibility for any other firearm to have fired the cartridges" recovered at the crime scene and that the witness "shall state his opinions and conclusions without characterisation as to the degree of certainty with which he holds them."162 The court based these restrictions on the 2009 NAS Report and the 2008 Ballistic Imaging Report. ${ }^{163}$

In Williams $v$ United States ${ }^{164}$ the appellant was arrested and prosecuted for murder with the use of a firearm. After searching the appellant's apartment, the police recovered a gun that, when test-fired, left markings on the bullets that appeared to match the markings on bullets recovered at the crime scene. After considering this evidence, a jury convicted the appellant. On appeal, the appellant argued that the firearm and tool mark examiner should not have been able to testify that the markings on the bullets

\footnotetext{
156 US v Diaz.

157 US v Taylor $663 \mathrm{~F}$ Supp 2d 1170 (DNM 2009).

158 United States v Anderson 2009 CF1 20672 (Sept 3, 2010).

159 US v Taylor $663 \mathrm{~F}$ Supp 2d 1170 (DNM 2009).

160 US v Willock 696 F Supp 2d 536 (D Md 2010).

161 Devasia and Koutsoudakis state that in a dispositive matter in US the magistrate does not have statutory authority to issue a final order, which means that parties decide if the magistrate must give the final order, and if the parties decline to consent to the grant of such authority in the case, the magistrate is left with only the authority to provide a Report and Recommendation ( $R$ \& $R$ ) for the district judge's consideration when ruling on the motion. Devasia and Koutsoudakis 2011 https://koehler-isaacs.com/2011/12/29/magistrate-judges-a-primer-for-younglawyers/.

162 US v Willock 696 F Supp 2d 536 (D Md 2010).

1632009 NAS Report 42, 153-155. Also see the 2008 Ballistic Imaging Report 1-5, 55, 82.

164 Williams v State 384 So 2d 1205, 1210-1211 (Ala Crim App 1980).
} 
recovered from the crime scene were unique or that he was without "any doubt" that these bullets were fired from the gun found with the appellant. With regard to this issue the appeal court quoted the case of Jones $v$ United States. ${ }^{165}$ In that case the court argued inter alia that tool mark and firearms examiners could not "[s]tate their conclusions with 'absolute certainty excluding all other possible firearms."'166 In the light of this, the appeal court held that "experts should not be permitted to testily that they are 100 per cent certain of a match, to the exclusion of all other firearms."167

In 2017 Jessica Brand ${ }^{168}$ referred to a murder case decided in 1993. The accused was convicted by the jury based on firearm testimony by the firearm experts. They declared that cartridges and bullets recovered from the crime scene matched the gun of the accused "to the exclusion of all other firearms". In 2017, the state agreed that the examiner should never have made such a statement and that the examiner should have said the convicted person's gun "could not be eliminated". The court granted the convicted person a new trial. ${ }^{169}$

Presiding officers should "place constraints" on what the forensic experts say in court. ${ }^{170}$

\subsection{Verification and peer-review}

Verification and peer-review are crucially important in order to confirm the value of the result and the conclusion reached by using the particular technique. Verification and peer-review are uncertain and of no importance if the techniques are not validated. Forensic practitioners should not suggest that peer-review or other verification procedures in themselves can somehow overcome or repair the absence of validation. Furthermore, for peer-review to be effective, the reviewer must be unaware of the original results. In this regard, peer-review and verification are most likely to help to reduce errors when they are conducted "where procedures are known to be valid and review is blind". ${ }^{171}$

\footnotetext{
165 Jones $v$ United States 27 A 3d 1130 (DC 2011).

166 Jones $v$ United States 27 A 3d 11301138 (DC 2011).

167 Williams $v$ State 384 So 2d 1205, 1210-1211 (Ala Crim App 1980).

168 Brand $2017 \mathrm{https}$ ://injusticetoday.com/faulty-forensics-explained-cd102d3f0a2e.

169 Brand 2017 https://injusticetoday.com/faulty-forensics-explained-cd102d3f0a2e.

$170 \quad$ See $R v$ Tang 200665 NSWLR 681; $R v$ T 2010 EWCA Crim 2439.

$171 \quad R \vee$ Tang 200665 NSWLR 681. This is not how most "peer-review" exercises operate within forensic science institutions.
} 


\subsection{Cognitive and contextual effects}

Forensic scientists could be exposed to some information that might not be relevant to their processing and interpretation of evidence, and this is problematic in that their interpretation and the value of their opinion evidence could be threatened. ${ }^{172}$ The problem which arises as a result of contextual and cognitive biases is also discussed in a report jointly made by the National Institute of Standards and Technology (NIST) and the NIJ. ${ }^{173}$ According to Edmond et al, where there is vulnerability, the only way to avoid being influenced inappropriately is "to restrict access to domainirrelevant information (or, more precisely, information with the potential to mislead)." ${ }^{174}$ Edmond further elucidates that the separation of roles: ${ }^{175}$

facilitates blind analysis while allowing analysts to have access to appropriate information thereby ensuring the case manager (and the institution) is informed about the overall case.

Another proposal in this regard involves sequential unmasking, where information is "gradually revealed to the analyst". ${ }^{176}$ Under this proposal, for example, an analyst might carry out an "initial examination of the trace evidence and limit their interpretation to the legible or salient parts of the sample before comparing it to the suspect sample."177 Of course, the process will depend on the type of trace evidence, but the idea behind this is to make the analyst blind to the information that has the potential to cause bias. ${ }^{178}$

Foster and Huber ${ }^{179}$ contend that "an emphasis on falsifying theories has an additional advantage in that it helps to overcome the effects of confirmation bias." 180 The bias in favour of confirming investigators' leads is

172 Edmond et al 2015 Law, Probability and Risk2.

173 "EWG, Latent Print Examination and Human Factors. Recently, NIJ and NIST have formed an expert group of psychologists to examine human factor issues in forensic science, and to guide all the domain expert groups on how to minimise bias and other cognitive issues." See OSAC 2014 http://www.nist.gov/forensics/osac/hfc.cfm.

174 Edmond et al 2015 Law, Probability and Risk 2.

175 Edmond et al 2015 Law, Probability and Risk 1.

176 Krane et al 2008 Journal of Forensic Sciences 1006.

177 Krane et al 2008 Journal of Forensic Sciences 1006.

178 Rosenthal and Rubin 1978 Behav Brain Sci 377.

179 Foster and Huber Judging Science 250.

180 Mahoney Scientist as Subject 155. "Confirmation bias is a phenomenon whereby scientists tend to settle on a theory at the outset and thereafter tend to look for data to confirm the theory, rather than trying to discredit or refute it." This phenomenon is illustrated in a paper by Garry et al 1994 Consciousness and Cognition 438, "where it is shown that mental health professionals investigating child abuse may too readily albeit unwittingly collaborate with the presumed victim to conjure up memories of abuse that never happened", as cited by Meintjes-van der Walt 2003 J Afr L 101. 
in most cases left unchecked because if a firearm has been considered to be an unique source of marks, the firearm examiners in that case are no longer examining "any other gun" to determine if it might produce tool marks "that do at least as good a job at matching the evidence tool marks."181

Related to confirmation bias are observer effects. It is important to falsify and test theories so as to avoid observer bias and other sources of human error in forensic examinations. ${ }^{182}$ The psychological theory of observer effects states that "external information provided to persons conducting analyses may taint their conclusions." ${ }^{183}$ This a serious problem in techniques with a subjective component. ${ }^{184}$ This type of information has serious effects if the expert is exposed to it. ${ }^{185}$

With regard to the issue of bias, the NRC committee proposed that a body of research to reform institutional procedures and workflows is needed to address the impact of bias. ${ }^{186}$ As the disciplines of forensic science rely on subjective assessments when matching characteristics, such research is urgently needed. ${ }^{187}$ The originally proposed National Institute for Forensic Science or a similar body should address contextual bias, in addition to supervising validation studies, determining error rates, and developing empirically driven standards and probabilistic forms of reporting results. ${ }^{188}$ This could happen through encouraging the establishment of research programmes on human observer bias and sources of human error in forensic science examinations. ${ }^{189}$ Programmes like this might involve studies aimed at determining the effects of contextual bias in forensic practice, such as studies to determine whether and to what extent the results of forensic analyses are influenced by knowledge regarding the background of the suspect and the investigator's theory of the case. ${ }^{190}$

\footnotetext{
181 Schwartz 2008 The Champion 48.

182 Breyer Reference Manual on Scientific Evidence 67.

183 Risinger et al 2002 CLR.

184 Risinger et al 2002 CLR.

1852009 NAS Report 139.

186 See Edmond 2015 Adel L Rev 47.

1872009 NAS Report 8, 14.

1882009 NAS Report 8, 14.

1892009 NAS Report 191.

1902009 NAS Report 24. In 2013 responsibility for reform was conferred on a committee of the National Institute of Standards and Technology (US). However, the NIFS that was envisaged by the NAS Report has not been created as yet.
} 


\section{How presiding officers can determine whether a bullet/cartridge comes from a specific firearm}

Firearm identification experts rely on markings on cartridges and projectiles to determine the link with a particular weapon, and in cases where firearm identification evidence is involved the court is concerned with how the marks associated with the suspect weapon were matched with other evidence. ${ }^{191}$ This is based on the assumption that "all firearms possess distinctive features that in turn impart distinctive markings onto bullets and cartridge casings when the weapon is fired."192 In order to determine whether the marks were fired from a particular weapon, firearm examiners use a comparison microscope. Under this comparison microscope bullets and cartridge casings recovered from the crime scene are compared with those test-fired from a seized weapon. ${ }^{193}$ The similarities and differences between the marks must be observed and recorded during this process. An examiner uses the observed information for the purposes of identification in order to reach a decision regarding a common source of the bullet or cartridge in question. ${ }^{194}$ After the matching has been completed, enlarged photographs of the marks should be made for the purpose of illustrating the correctness of the examiner's conclusions. ${ }^{195}$

The significant factors the presiding officer should consider in assessing whether a particular firearm is the source of a mark on a questioned bullet or cartridge case are: (i) similarities between impressions left by different firearms and (ii) differences observed during the comparison between impressions left by the same firearm. ${ }^{196}$ In addition, presiding officers need to make sure that statements on matches made "should be supported by the work that was done in the laboratory by the notes and documentation made by examiners and by proficiency testing or established error rates for individual examiners in the field and in that particular laboratory, but should not overreach to make extreme probability statements." ${ }^{197}$ In General Electric Co $v$ Joiner ${ }^{198}$ the US Supreme Court cautioned that judges and

\footnotetext{
191 Dack 2014 https://scholarship.shu.edu/cgi/viewcontent.cgi?article=1631\& context=student_scholarship 6 .

192 Dack 2014 https://scholarship.shu.edu/cgi/viewcontent.cgi?article=1631\&context= student_scholarship 6.

193 Commonwealth v Pytou Heang 458 Mass 827 837-838, 942 NE 2d 927938 (2011). 2009 NAS Report 150-151; 2008 Ballistic Imaging Report 11, 86; AFTE Criteria for Identification Committee 1992 AFTE Journal 86.

$194 \quad$ Riva and Champod 2014 Journal of Forensic Sciences 641.

195 Inbau 1934 Am Inst Crim L \& Criminology 829.

196 Riva and Champod 2014 Journal of Forensic Sciences 641.

1972008 Ballistic Imaging Report 82.

198 General Electric Co v Joiner 522 US 136146 (1997).
} 
jurors must not engage in speculation about "validity and reliability or trace the probative value of evidence from the subjective beliefs of practitioners based on impressions of the apparent value of experience and independence, or their demeanour, confidence and resilience during crossexamination."199 According to the court "there should be information supporting reliability and facilitating evaluation."200

\section{Conclusion}

Although firearm identification has been described as unreliable, it has played an important role in identifying the perpetrators of crime. ${ }^{201}$ If efforts are made to validate this type of evidence, it could generate "legitimate convictions" that do not change even when there is a "post-conviction relief appeals process" in the criminal justice system. ${ }^{202}$

The 2009 NAS Report is particularly critical of weaknesses in the scientific underpinnings of a number of the forensic disciplines routinely used in the criminal justice system, including firearm identification. That report shows that firearm identification has not yet reached a stage where it can be regarded as reliable evidence. ${ }^{203}$

Science is developing exponentially, and investigating officers, lawyers, magistrates, judges and even forensic technicians cannot reasonably be expected to be au fait with cutting-edge developments in the field of forensic science and technology. For this reason, continuing education, as is a requirement in the medical profession, is urgently necessary in the field of forensic science. The introduction in South Africa of the NRC recommendation regarding "legal education programmes for law students, practitioners and judges"204 would be logistically uncomplicated and relatively inexpensive and would have the potential significantly to relieve part of the enormous burden on prosecutors, defence lawyers, magistrates and judges, and above all would have the potential to go some way towards improving the scientific validity of firearm identification.

If laboratory technicians, forensic scientists, police investigators, prosecutors, defence lawyers, magistrates and judges would heed the serious criticism of the current firearm identification practices indicated

\footnotetext{
199 General Electric Co v Joiner 522 US 136146 (1997).

200 General Electric Co v Joiner 522 US 136146 (1997).

201 Cooper 2016 JPSL 2.

202 Cooper 2016 JPSL 2.

2032009 NAS Report 138.

2042009 NAS Report 28, 234.
} 
above, this would engender a courtroom culture which would be even more circumspect in dealing with firearm identification than before, by incisively interrogating the scientific foundations on which the expert evidence is based in order to decide what weight should be attached to the evidence.

The Daubert rules and other precautionary measures in dealing with firearm identification evidence in court have become the gold standard for the scientific evaluation of evidence based on forensic science in some jurisdictions, and even although the application of the Daubert rules is not yet mandatory in South Africa, ${ }^{205}$ magistrates and judges could serve justice by using those criteria to determine the weight which should be attached to forensic evidence in general and to firearm identification in particular.

\section{Bibliography}

\section{Literature}

Acharya 2013 Dalhousie LJ

Acharya $\mathrm{N}$ "Law's Treatment of Science: From Idealization to Understanding" 2013 Dalhousie LJ 57-?

AFTE Criteria for Identification Committee 1992 AFTE Journal

AFTE Criteria for Identification Committee "Theory of Identification, Range of Striae Comparison Reports and Modified Glossary Definitions - AFTE Criteria for Identification Committee Report" 1992 AFTE Journal 1-390

AFTE Glossary 1998 AFTE Journal

AFTE Glossary "Theory of Identification as it relates to Toolmarks" 1998 AFTE Journal 86-88

Black Black's Law Dictionary

Black HC Black's Law Dictionary $5^{\text {th }}$ ed (West St Paul, Minn 1979)

Black 1988 SUL Rev

Black MR "Cross Examination: The Greatest Legal Engine for the Discovery of Truth: A Comparative Analysis of the American and English Rules of Cross-Examination" 1988 SUL Rev 397-405

205 There is a growing awareness of the Daubert rules. See Bee $v$ Road Accident Fund 20184 SA 366 (SCA); Sedma Removals CC v Never General Dealers CC 2018 ZAGPPHC 789 (19 October 2018); SMD Telecommunications CC v Mutual and Federal Insurance Company Ltd 2009 ZAWCHC 147 (18 May 2009); S v Rohde 20191 All SA 740 (WCC). 
Bonnie 2012 Suffolk J Trial \& App Advoc

Bonnie L "Firearms Identification: The Need for a Critical Approach to, and Possible Guidelines for, the Admissibility of 'Ballistics Evidence'" 2012 Suffolk J Trial \& App Advoc 54-442

Breyer Reference Manual on Scientific Evidence

Breyer S Reference Manual on Scientific Evidence (Federal Judicial Center Washington DC 2000)

Commission on Identifying the Needs of the Forensic Science Community Strengthening Forensic Science in the United States

Commission on Identifying the Needs of the Forensic Science Community, Research Council of the National Academy of Sciences Strengthening Forensic Science in the United States: A Path Forward (National Research Press Washington, DC 2009)

Committee to Assess the Feasibility, Accuracy, and Technical Capability of a National Ballistics Database Ballistic Imaging

Committee to Assess the Feasibility, Accuracy, and Technical Capability of a National Ballistics Database, National Research Council of the National Academies Ballistic Imaging (National Academies Press Washington, DC 2008)

Cooper 2014 TM Cooley L Rev

Cooper SL "Judicial Responses to Challenges to Firearms-Identification Evidence: A Need for New Judicial Perspectives on Finality" 2014 TM Cooley L Rev 457-465

Cooper 2016 JPSL

Cooper SL "Forensic Science Identification Evidence: Tensions between Law and Science" 2016 JPSL 1-35

Cunliffe 2013 AJFS

Cunliffe E "Independence, Reliability and Expert Testimony in Criminal Trials" 2013 AJFS 284-295

Dutton 2005 AFTE Journal

Dutton G "Commentary: Ethics in Forensic Firearms Investigation" 2005 AFTE Journal 79-82

Edmond 2013 UNSWLJ

Edmond G "[Ad]ministering Justice: Expert Evidence and the Professional Responsibilities of Prosecutors" 2013 UNSWLJ 921-953 
Edmond 2015 Adel L Rev

Edmond G "What Lawyers should Know about the Forensic Sciences" 2015 Adel L Rev 33-106

Edmond and Meintjes-van der Walt 2014 SALJ

Edmond $G$ and Meintjes-van der Walt L "Blind Justice? Forensic Science and the Use of Closed Circuit Television Images as Identification Evidence in South Africa" 2014 SALJ 109-148

Edmond et al 2013 U Denv Crim L Rev

Edmond $\mathrm{G}$ et al "Admissibility Compared: The Reception of Incriminating Expert Evidence in Four Adversarial Jurisdictions" 2013 U Denv Crim L Rev 31-109

Edmond et al 2014 Aust Bar Rev

Edmond $\mathrm{G}$ et al "How to Cross-examine Forensic Scientists: A Guide for Lawyers" 2014 Aust Bar Rev 174-196

Edmond et al 2015 Law, Probability and Risk

Edmond $\mathrm{G}$ et al "Contextual Bias and Cross-contamination in the Forensic Sciences: The Corrosive Implications for Investigations, Plea Bargains, Trials and Appeals" 2015 Law, Probability and Risk 1-25

Edmond et al 2016 AJFS

Edmond G et al "Model Forensic Science" 2016 AJFS 1-42

Faurie Admissibility and Evaluation of Scientific Evidence

Faurie A The Admissibility and Evaluation of Scientific Evidence in Court (LLM-dissertation University of South Africa 2000)

Foster and Huber Judging Science

Foster K and Huber P Judging Science (MIT Press Cambridge, Mass 1999)

Gabel 2014 J Crim L \& Criminology

Gabel JD "Realizing Reliability in Forensic Science from the Ground Up" 2014 J Crim L \& Criminology 284-351

Garry et al 1994 Consciousness and Cognition

Garry M et al "Memory: A River Runs Through It" 1994 Consciousness and Cognition 438-451

Gershman 2003 Okla City U L Rev

Gershman BL "Misuse of Scientific Evidence by Prosecutors" 2003 Okla City $U L \operatorname{Rev} 1-22$ 
Giannelli and McMunigal 2007 Fordham L Rev

Giannelli $\mathrm{P}$ and McMunigal K "Prosecutors, Ethics, and Expert Witnesses" 2007 Fordham L Rev 1493-1537

Giannelli, Imwinkelried and Peterson "Reference Guide on Forensic Identification Expertise"

Giannelli PC, Imwinkelried EJ and Peterson JL "Reference Guide on Forensic Identification Expertise" in National Research Council Reference Manual on Scientific Evidence (National Academies Press Washington, DC 2011) ch 16

Green and Zacharias 2004 Wis L Rev

Green BA and Zacharias FC "Prosecutorial Neutrality" 2004 Wis L Rev 837890

Grzybowski and Murdock 1998 AFTE Journal

Grzybowski RA and Murdock $J$ "Firearm and Toolmark Identification Meeting the Daubert Challenge" 1998 AFTE Journal 3-14

Grzybowski et al 2003 AFTE Journal

Grzybowski RA et al "Firearm/Toolmark Identification: Passing the Reliability Test under Federal and State Evidentiary Standards" 2003 AFTE Journal 1-34

Gunther 1932 Mechanical Engineering

Gunther CO "Markings on Bullets and Shells Fired from Small Arms" 1932 Mechanical Engineering 334-345

Hatcher Textbook of Firearms Investigation

Hatcher JS Textbook of Firearms Investigation, Identification and Evidence (Small Arms Technical Publishing Marines, NC 1935)

Ho Philosophy of Evidence Law

Ho HL A Philosophy of Evidence Law: Justice in the Search for Truth (Oxford University Press London 2008)

Inbau 1934 Am Inst Crim L \& Criminology

Inbau FE "Scientific Evidence in Criminal Cases" 1934 Am Inst Crim L \& Criminology 825-844

Inbau 1999 J Crim L \& Criminology

Inbau FE "Firearms Identification: Ballistics" 1999 J Crim L \& Criminology 1293-1314 
Irwin and Wynne Misunderstanding Science?

Irwin A and Wynne B Misunderstanding Science? The Public Reconstruction of Science and Technology (Cambridge University Press Cambridge 2001)

Koehler and Meixner 2016 J Crim L \& Criminology

Koehler JJ and Meixner JB "An Empirical Research Agenda for the Forensic Sciences" 2016 J Crim L \& Criminology 1-34

Koen and Bowers Forensic Science Reform Koen WJ and Bowers CM Forensic Science Reform: Protecting the Innocent (Elsevier Amsterdam 2016)

Krane et al 2008 Journal of Forensic Sciences

Krane DE et al "Sequential Unmasking: A Means of Minimizing Observer Effects in Forensic DNA Interpretation" 2008 Journal of Forensic Sciences 1006-1007

Laurin 2015 Tex L Rev

Laurin JE "Criminal Law's Science Law: How Criminal Justice Meets Changed Scientific Understanding" 2015 Tex L Rev 1751-1765

Law Commission Expert Evidence in Criminal Proceedings

Law Commission Expert Evidence in Criminal Proceedings in England and Wales: Report Presented to Parliament Pursuant to Section 3(2) of the Law Commissions Act 1965 (The Stationary Office London 2011)

Luna and Wade 2010 Wash \& Lee L Rev

Luna E and Wade M "Prosecutors as Judges" 2010 Wash \& Lee L Rev 1413-1532

Mahoney Scientist as Subject

Mahoney MJ Scientist as Subject: The Psychological Imperative (Ballinger Press Cambridge 1976)

Meintjes-van der Walt Expert Evidence in the Criminal Justice Process Meintjes-van der Walt $L$ Expert Evidence in the Criminal Justice Process: A Comparative Perspective (Rozenberg Press Amsterdam 2001)

Meintjes-van der Walt L $2003 \mathrm{~J}$ Afr $L$

Meintjes-van der Walt $L$ "The Proof of the Pudding: The Presentation and Proof of Expert Evidence in South Africa" 2003 J Afr L 88-106 
Michelson Crime Scene Investigation

Michelson RS Crime Scene Investigation: An Introduction to CSI (Law Tech San Clemente 2009)

Mnookin et al 2011 UCLA L Rev

Mnookin J et al "The Need for a Research Culture in the Forensic Sciences" 2011 UCLA L Rev 725-761

Moriarty $2007 \mathrm{Neb}$ L Rev

Moriarty JC "'Misconvictions', Science and the Ministers of Justice" 2007 Neb L Rev 1-42

Mulkay 1976 Soc Sci Inf

Mulkay MJ "Norms and Ideology in Science" 1976 Soc Sci Inf 637-656

Murdock et al 2017 Journal of Forensic Science

Murdock JE et al "The Development and Application of Random Match Probabilities to Firearm and Toolmark Identification" 2017Journal Forensic Science 619-625

Mutsavi Reliability of Firearm Identification in South Africa

Mutsavi $\mathrm{T}$ The Reliability of Firearm Identification in South Africa: A Comparative Perspective (LLM-dissertation University of Fort Hare 2018)

Nichols 2006 California Association of Criminalists News

Nichols R "The Scientific Foundations of Firearms and Toolmark Identification - A Response to Recent Challenges" 2006 California Association of Criminalists News 8-27

Nichols 2007 Journal of Forensic Science

Nichols R "Defending the Scientific Foundations of the Firearms and Toolmark Identification Discipline: Responding to Recent Challenges" 2007 Journal of Forensic Science 581-593

President's Council of Advisors Report to the President President's Council of Advisors on Science and Technology Report to the President - Forensic Science in Criminal Courts: Ensuring Scientific Validity of Feature-Comparison Methods (Executive Office of the President Washington, DC 2016)

Puzniak 2000 Court Review

Puzniak J "Expert Evidence: The Road from Daubert to Joiner and Kumho Tire" 2000 Court Review 32-54 
Raeder 2007 Fordham L Rev

Raeder MS "See No Evil: Wrongful Convictions and the Prosecutorial Ethics of Offering Testimony by Jailhouse Informants and Dishonest Experts" 2007 Fordham L Rev 1413-1452

Risinger et al 2002 CLR

Risinger DM et al "The Daubert/Kumho Implications of Observer Effects in Forensic Science: Hidden Problems of Expectation and Suggestion" 2002 CLR 1-56

Riva and Champod 2014 Journal of Forensic Sciences

Riva $\mathrm{F}$ and Champod C "Automatic Comparison and Evaluation of Impressions Left by a Firearm on Fired Cartridge Cases" 2014 Journal of Forensic Sciences 637-647

Rosenthal and Rubin 1978 Behav Brain Sci

Rosenthal R and Rubin DB "Interpersonal Expectancy Effects: The First 345 Studies" 1978 Behav Brain Sci 377-386

Saks 2001 Clev St L Rev

Saks MJ "Scientific Evidence and the Ethical Obligations of Attorneys" 2001 Clev St L Rev 421-437

Schwartz 2005 Colum Sci \& Tech L Rev

Schwartz A "A Systemic Challenge to the Reliability and Admissibility of Firearms and Toolmark Identification" 2005 Colum Sci \& Tech L Rev 1-42

Schwartz 2008 The Champion

Schwartz A "Challenging Firearms and Toolmark Identification - Part Two" 2008 The Champion 44-51

Thornton 1994 Shepard's Expert and Scientific Evidence Quarterly Thornton JI "Courts of Law v Courts of Science: A Forensic Scientist's Reaction to Daubert" 1994 Shepard's Expert and Scientific Evidence Quarterly 475-485

\section{Case law}

Bee v Road Accident Fund 20184 SA 366 (SCA)

Bentley v Scully 41 F 3d 818 (2d Cir 1994)

Burchett v State 172 NE 555 (Ohio Ct App 1930) 
Burge v State 282 So 2d 223 (Miss 1973)

Commonwealth v Hoss 283 A 2d 58 (Pa 1971)

Commonwealth v Meeks Nos 2002-10961, 2003-10575, 2006 WL 2819423 (Mass Super Ct Sept 28, 2006)

Commonwealth v Pytou Heang 458 Mas 827, 942 NE 2d 927 (2011)

Commonwealth v Whitacre 878 A 2d 96 (Pa Sup Ct 2005)

Daubert v Merrell Dow Pharmaceuticals Inc 509 US 579 (1993)

Evans v Commonwealth 19 SW 2d 1091 (Ky 1929)

General Electric Co v Joiner 522 US 136 (1997)

In Re Paoli Railroad Yard PCB Litigation 35 F 3d 717 (3rd Cir 1994)

Jones v United States 27 A 3d 1130 (DC 2011)

Kumho Tire Co v Carmichael 526 US 137 (1999)

Luttrell v Commonwealth 952 SW 2d 216 (Ky 1997)

People v Fisher 172 NE 743 (III 1930)

People v Horning 102 P 3d 228 (Cal 2004)

$R v$ Jacobs 1940 TPD 142

$R v T 2010$ EWCA Crim 2439

$R v$ Tang 200665 NSWLR 681

Ramirez $v$ State of Florida (Florida Supreme Court) (unreported) case number SC92975 of 20 December 2001

Resurrection Gold Mining Co v Fortune Gold Mining Co 129 F 668 ( $8^{\text {th }}$ Cir 1904)

S v Rohde 20191 All SA 740 (WCC)

Sedma Removals CC v Never General Dealers CC 2018 ZAGPPHC 789 (19 October 2018) 
SMD Telecommunications CC v Mutual and Federal Insurance Company Ltd 2009 ZAWCHC 147 (18 May 2009)

State $v$ Davidson 509 SW 3d 156 (Tenn 2017)

State $v$ Mack 653 NE 2d 329 (Ohio 1995)

State $v$ Samonte 928 P 2d 1 (Haw 1996)

Tuite v The Queen 2015 VSCA 148

Twine v Naidoo 20181 All SA 297 (GJ)

United States v Anderson 2009 CF1 20672 (Sept 3, 2010)

United States v Ashburn 88 F Supp 3d 239 (EDNY 2015)

United States v Diaz No CR 05-00167 WHA, 2007 WL 485967 (ND Cal Feb 12, 2007)

United States v Foster 300 F Supp 2d 375 (D Md 2004)

United States v Glynn 578 F Supp 2d 567 (SDNY 2008)

United States v Green 405 F Supp 2d 104 (D Mass 2005)

United States v Hicks 389 F 3d 514 (5th Cir 2004)

United States $v$ Hines 55 F Supp 2d 6267 (D Mass 1999)

United States v Mikos No 02 CR 137, 2003 WL 22922197 (ND III 2003)

United States v Monteiro United 407 F Supp 2d 351 (D Mass 2006)

United States v Natson 469 F Supp 2d 1253 (MD Ga 2007)

United States v Santiago 199 F Supp 2d 101 (SDNY 2002)

United States v Wolff 5 MJ 923 (NCMR 1978)

US v Baines 573 F 3d 979 (2009)

US v Taylor 663 F Supp 2d 1170 (DNM 2009)

US v Willock 696 F Supp 2d 536 (D Md 2010) 
Velevski v The Queen 2002187 ALR 233

White Burgess Langille v Abbott and Haliburton Co 2015 SCC 23

Williams v State 384 So 2d 1205 (Ala Crim App 1980)

\section{Internet sources}

Brand $2017 \quad$ https://injusticetoday.com/faulty-forensics-explainedcd102d3f0a2e

Brand J 2017 Faulty Forensics: Explained https://injusticetoday.com/faultyforensics-explained-cd102d3f0a2e accessed 22 November 2017

Collaborative Testing Services Inc 2018 https://cts-forensics.com/program3.php

Collaborative Testing Services Inc 2018 Firearms \& Toolmarks https://ctsforensics.com/program-3.php accessed 18 November 2018

Cromwell $2011 \quad$ http://www.scottishlawreports.org.uk/publications/ macfadyen-2011.html

Cromwell T 2011 The Challenges of Scientific Evidence http://www.scottishlawreports.org.uk/publications/macfadyen-2011.html accessed 27 July 2016

Dack $2014 \quad$ https://scholarship.shu.edu/cgi/viewcontent.cgi? article $=1631 \&$ context=student_scholarship

Dack JR 2014 Using Forensic Ballistics in the Courtroom https://scholarship.shu.edu/cgi/viewcontent.cgi?article $=1631$ \&context=stud ent_scholarship accessed 2 December 2019

Devasia and Koutsoudakis 2011 https://koehlerisaacs.com/2011/12/29/magistrate-judges-a-primer-for-young-lawyers/ Devasia C and Koutsoudakis A 2011 Magistrate Judges: A Primer for Young Lawyers https://koehler-isaacs.com/2011/12/29/magistrate-judges-aprimer-for-young-lawyers/ accessed 31 August 2017

Dinzeo 2017 https://www.courthousenews.com/skepticism-forensicmethods-urged-9th-circuit-conference

Dinzeo M 2017 Skepticism of Forensic Methods Urged at 9th Circuit Conference https://www.courthousenews.com/skepticism-forensicmethods-urged-9th-circuit-conference/ accessed 7 August 2017

Federal Rules of Evidence 2020 https://www.rulesofevidence.org/articleiv/rule-401 
Federal Rules of Evidence 2020 Rule 401 - Test for Relevant Evidence https://www.rulesofevidence.org/article-iv/rule-401 accessed 7 January 2020

Federal Rules of Evidence 2011 https://www.law.cornell.edu/ rules/fre/rule_702

Federal Rules of Evidence 2011 Rule 702: Testimony by Expert Witnesses https://www.law.cornell.edu/rules/fre/rule_702 accessed 7 January 2020

Hogan Lovells 2016 https://www.hoganlovells.com/en/publications/ confirmation-bias-and-the-law

Hogan Lovells 2016 Confirmation Bias and the Law https://www.hoganlovells.com/en/publications/confirmation-bias-and-thelaw accessed 14 June 2018

National Academies of Sciences Engineering Medicine 2008 https://www.nas.edu/evolution/TheoryOrFact.html

National Academies of Sciences Engineering Medicine 2008 Is Evolution a Theory or a Fact? https://www.nas.edu/evolution/TheoryOrFact.html accessed 27 April 2017

OSAC 2014 http://www.nist.gov/forensics/osac/hfc.cfm

Organisation of Scientific Area Committees 2014 OSAC on Forensic Science http://www.nist.gov/forensics/osac/hfc.cfm accessed 5 August 2017

\section{List of Abbreviations}

AAFS

Adel L Rev

AFTE

AJFS

Am Inst Crim L \&

Criminology

Aust Bar Rev

Behav Brain Sci

CLR

CICJ

Clev St L Rev

Colum Sci \& Tech L Rev
American Academy of Forensic Sciences

Adelaide Law Review

Association of Firearm and Toolmark

Examiners

Australian Journal of Forensic Science

American Institute of Criminal Law and Criminology

Australian Bar Review

Behavioral and Brain Sciences

California Law Review

Current Issues Criminal Justice

Cleveland State Law Review

Columbia Science and Technology Law

Review 


\begin{tabular}{ll} 
Crim LJ & Criminal Law Journal \\
CTS & Collaborative Testing Service \\
Dalhousie LJ & Dalhousie Law Journal \\
FBI & Federal Bureau of Investigation \\
Fordham L Rev & Fordham Law Review \\
Forensic Sci Policy Manage & Forensic Science Policy and Management: \\
& An International Journal \\
J Afr L & Journal of African Law \\
J Crim L \& Criminology & Journal of Criminal Law and Criminology \\
JPSL & Journal of Philosophy, Science and Law \\
MULR & Melbourne University Law Review \\
Neb L Rev & Nebraska Law Review \\
NAS & National Academy of Sciences \\
NIJ & National Institute of Justice \\
NIST & National Institute of Standards and \\
& Technology \\
NRC & National Research Council \\
Okla City U L Rev & Oklahoma City University Law Review \\
OSAC & Organisation of Scientific Area Committees \\
Pace L Rev & Pace Law Review \\
PCAST & President's Council of Advisors on Science \\
& and Technology \\
SALJ & South African Law Journal \\
Soc Sci Inf & Social Science Information \\
Suffolk J Trial \& App Advoc & Suffolk Journal of Trial and Appellate \\
& Advocacy \\
SUL Rev & Southern University Law Review \\
Tex L Rev & Texas Law Review \\
TM Cooley L Rev & Thomas Michael Cooley Law Review \\
U Denv Crim L Rev & University of Denver Criminal Law Review \\
UCLA L Rev & UCLA Law Review \\
UNSWLJ & University of New South Wales Law Journal \\
US & United States \\
USA & United States of America \\
Wash \& Lee L Rev & Washington and Lee Law Review \\
Wis L Rev & Wisconsin Law Review \\
& \\
\hline &
\end{tabular}

